\title{
Influence of Malpractice History on the Practice of Screening and Surveillance for Barrett's Esophagus
}

\author{
Joel H. Rubenstein, M.D., M.Sc., ${ }^{1,2}$ Sameer D. Saini, M.D., ${ }^{2}$ Latoya Kuhn, M.P.H., ${ }^{1}$ \\ Laurence McMahon, M.D., M.P.H., ${ }^{1,2}$ Pratima Sharma, M.D., ${ }^{2}$ Darrell S. Pardi, M.D., ${ }^{3}$ \\ and Philip Schoenfeld, M.D., M.S.Ed., M.Sc. (Epi) ${ }^{1,2}$ \\ ${ }^{1}$ Ann Arbor Veterans Affairs Medical Center, Ann Arbor, Michigan; ${ }^{2}$ University of Michigan Medical School, \\ Ann Arbor, Michigan; and ${ }^{3}$ Mayo Clinic College of Medicine, Rochester, Minnesota
}
BACKGROUND: Gastroenterologists' approach to surveillance for Barrett's esophagus is variable. We hypothesized that financial incentives and concerns over malpractice litigation influence gastroenterologists' usual practices regarding screening and surveillance.

METHODS: $\quad$ We surveyed gastroenterologists $(N=224)$ regarding their usual practice of screening or surveillance for Barrett's esophagus, belief in the efficacy of screening, knowledge of published guidelines, demographic factors, compensation structure, volume of endoscopies, and malpractice history. Practices were characterized as aggressive or conservative in the utilization of services compared with a published guideline.

RESULTS: $\quad$ Twenty-one percent of attending gastroenterologists reported being identified as a defendant in at least one malpractice suit. Prior malpractice defendants had practiced gastroenterology longer and performed a higher volume of endoscopies, but had similar knowledge regarding published screening guidelines to those who had not been defendants. They were more likely to be aggressive rather than conservative in screening and surveillance for Barrett's esophagus (odds ratio [OR] 3.6, 95\% confidence interval $[\mathrm{Cl}]$ 1.1-12), and remained so after controlling for other factors. In particular, they were more likely to recommend screening for populations with a lower risk of development of cancer, and to perform more frequent surveillance for low-grade dysplasia. Other factors were not associated with aggressive practice, including compensation structure.

CONCLUSIONS: History of at least one prior malpractice suit appears to be associated with the more aggressive use of endoscopic screening and surveillance for Barrett's esophagus, irrespective of physician belief regarding the efficacy of that strategy in reducing mortality. Hypervigilance and fear of future malpractice suits may drive this increased use.

(Am J Gastroenterol 2008;103:842-849)

\section{INTRODUCTION}

Despite being an uncommon cancer, the incidence of esophageal adenocarcinoma (EAC) is rising quickly (1). As the precursor of EAC is believed to be Barrett's esophagus (2), an attractive strategy for decreasing mortality from EAC would be to endoscopically screen for Barrett's esophagus, and to perform endoscopic surveillance in those patients found to harbor Barrett's esophagus. Multiple gastroenterology societies recommend such strategies for patients with symptoms of gastroesophageal reflux disease (GERD) (36), but the practice remains controversial due to the unproven efficacy of screening, the limited impact that such a program would have on the burden of disease in the population, only modest ability to predict which patients will develop cancer, and the poor long-term survival from all but intramucosal esophageal cancer (7-10). In practice, a wide range of surveillance patterns for patients with documented Barrett's esophagus has been reported among gastroenterologists (1116), but there has been little published regarding the practice patterns of initial screening (17). Furthermore, little is known regarding the factors that may influence practice patterns of individual gastroenterologists.

Financial incentives for performing endoscopy might influence gastroenterologists to be more aggressive in the use of endoscopy for this purpose. A previous study found that gastroenterologists receiving compensation predominantly through fee-for-service were less likely to adhere to recommended surveillance intervals (12). That study did not detail on whether compensation structure was associated with more aggressive or less aggressive surveillance than recommended; it also did not address screening practices. In the same survey, gastroenterologists reported that concerns regarding malpractice suits were factors influencing their 
disagreement with published guidelines of surveillance (12). Some Californian gastroenterologists have cited medicolegal concerns as a reason why they perform screening and surveillance despite not believing it to be efficacious (17). However, such malpractice concerns might be falsely offered in a survey to misrepresent the stronger financial incentives for performing endoscopy. We hypothesized that financial incentives for performing endoscopic procedures and fear of malpractice litigation are both associated with the aggressive practice of screening and surveillance for Barrett's esophagus, independent of a gastroenterologist's perception regarding the efficacy of screening and surveillance for reducing mortality. We aimed to estimate these effects objectively while avoiding potential misrepresentations of influential factors by selfreport. We, therefore, surveyed gastroenterologists regarding their usual practice, malpractice history, and compensation structure without notifying the subjects of our hypotheses.

\section{MATERIALS AND METHODS}

\section{Subjects}

Subjects were recruited from among gastroenterologists attending either the 2006 William Steinberg Board Review in Gastroenterology or the 2006 Mayo Clinic Gastroenterology and Hepatology Board Review. Attendees at these courses include attending gastroenterologists preparing for mandated recertification in gastroenterology, attending gastroenterologists interested in receiving continued medical education credit, as well as gastroenterology fellows or attending gastroenterologists who recently completed fellowship and are preparing for initial certification in gastroenterology. For the associations with compensation structure and malpractice history, the analyses focused on the attending gastroenterologists.

\section{Questionnaire}

The questionnaire was introduced by a written statement that the survey was intended to help understand the utility of currently published guidelines regarding gastrointestinal cancer screening and surveillance. The subjects were not informed of the a priori hypotheses regarding the associations with compensation structure or malpractice history. The questionnaire included eight brief clinical scenarios regarding patients with uninvestigated GERD symptoms (all well controlled on proton pump inhibitor therapy), patients with GERD but no Barrett's esophagus or erosive esophagitis, and patients with Barrett's esophagus, both with and without dysplasia. For each scenario, the respondents were asked to choose among multiple choices regarding their usual practice in each scenario. Respondents were also tested on their knowledge of the published guideline from the American College of Gastroenterology (ACG) regarding each scenario (3). This guideline was chosen as it is phrased as an imperative ("should undergo screening"), in contrast to the medical position statement of the American Gastroenterology Association that is phrased as a suggestion ("may be of value"), and the guideline of the American Society for Gastrointestinal Endoscopy ("should be considered") $(4,6)$. The guidelines were not reviewed in detail during the courses, but general lectures on esophageal disorders did occur before the surveys were distributed. After the clinical scenarios, respondents were requested to estimate what "proportion of deaths from esophageal adenocarcinoma, do you believe, is currently preventable by using appropriate screening and surveillance," by placing an X on a visual analog scale ranging from 0 to $100 \%$. A similar question was posed regarding screening for colorectal cancer (CRC). Respondents were then queried regarding demographic data, and practice characteristics, including practice setting (private, academic, and mixed), private practice type (single specialty, multispecialty, solo, and not applicable), compensation structure (salaried without productivity incentives, salaried with productivity incentives, and productivitybased without salary), and volume of endoscopies. Finally, respondents were queried whether they had "ever been identified as a defendant in a malpractice suit." The study was granted a waiver of informed consent by the institutional review board of the University of Michigan Medical School.

\section{Statistical Analysis}

For each clinical scenario, the respondents' usual practice was compared with the published guidelines of ACG to determine if the practice was more aggressive (i.e., shorter interval to repeat surveillance), more conservative (i.e., not performing initial screening), or identical to the society guidelines (3). For example, if the gastroenterologists responded that they usually perform surveillance of Barrett's esophagus without dysplasia annually, the practice would be characterized as aggressive, and if they perform surveillance every $5 \mathrm{yr}$, it would be characterized as conservative. A composite aggressiveness score was created for each respondent by subtracting the proportion of provided responses that were conservative from the proportion of provided responses that were aggressive, producing a score with a range from -1 to +1 . Each respondent was then categorized as "aggressive," "moderate," or "conservative" on the basis of tertiles of the composite score. In this way, the respondents were compared among themselves rather than against a particular guideline.

The perceived relative efficacy of screening and surveillance for EAC was calculated by dividing the proportion of cancer deaths perceived preventable by screening and surveillance for EAC by the proportion of cancer deaths perceived preventable by screening for CRC. Values greater than 1.0 imply that the respondent believes that screening for EAC is more efficacious than screening for $\mathrm{CRC}$, and values less than 1.0 imply a belief that screening for EAC is less efficacious. For the purpose of logistic regression, this variable was log transformed.

Comparisons in continuous variables between groups were made using $t$-tests (for two groups) or analysis of variance (ANOVA, for more groups). Comparisons in categorical variables between groups were made using $\chi^{2}$ tests. Logistic 
regression was performed on the likelihood of being aggressive rather than conservative, and on the likelihood of having been identified as a defendant in a malpractice suit. Stepwise forward logistic regression was performed using the likelihood ratio test with a threshold of $P<0.10$. The primary outcomes were the odds ratios (OR) for aggressive practice based on malpractice history and compensation structure. Using the general rule of 10 outcomes per factor, we expected to need a sample size of 150 (50 aggressive respondents) in order to also evaluate the effects of perceived efficacy and years in practicing gastroenterology a priori. All analyses were performed using SAS 9.1 (SAS Institute, Cary, NC).

\section{RESULTS}

\section{Demographics of Respondents}

The survey was completed by 224 gastroenterologists (70\% men, median age $38 \mathrm{yr}$ ), out of 543 attendees at the two courses. Twenty-five percent of respondents were fellows; attendings (those who had completed fellowship training) had been practicing gastroenterology on average 8.9 yr (range 0 $35 \mathrm{yr}$ ). Female attendings had been in practice for a shorter duration than male attendings $(5.8 \pm 7.4 \mathrm{yr} v s 9.9 \pm 9.3 \mathrm{yr}$, $P=0.02$ ). Demographics of the attending gastroenterologists are shown in Table 1. Most attendings were in singlespecialty, private practices with a high volume of upper endoscopies. Twenty-one percent of attendings responded that they had been identified as a defendant in a malpractice suit in the past. The compensation structures were nearly evenly divided. Practice setting was associated with compensation structure $(P<0.001)$ such that attendings in private practice were more likely to receive compensation based on productivity without any salary than those in academic practice $(34 \%$ vs $0 \%$ ), and those in academic practice were more likely to be salaried without productivity incentives than those in private practice ( $74 \%$ vs $27 \%$ ). All but nine attendings responded to

Table 1. Demographics of Attending Gastroenterologists

\begin{tabular}{ll}
\hline Scheduled for GI Board exam & \\
Scheduled for certification exam & $44 \%$ \\
Scheduled for recertification exam & $17 \%$ \\
Not scheduled for either exam & $39 \%$ \\
Practice setting & \\
$\quad$ Private & $76 \%$ \\
Academic & $16 \%$ \\
Mixed & $8 \%$ \\
Private practice type & \\
Single specialty & $63 \%$ \\
Multiple-specialty & $23 \%$ \\
Solo practice & $12 \%$ \\
Volume of upper endoscopies & \\
10 or fewer per week & $33 \%$ \\
Greater than 10 per week & $67 \%$ \\
Compensation structure & \\
Salaried without productivity incentives & $35 \%$ \\
Salaried with productivity incentives & $37 \%$ \\
Productivity-based without salary & $27 \%$ \\
Identified in malpractice suit & $21 \%$ \\
\hline
\end{tabular}

the question regarding compensation structure, and all but one responded to the question regarding malpractice.

\section{Practice Patterns in Clinical Scenarios}

Respondents were more likely to screen GERD patients who were older men with a long duration of frequent symptoms than patients with other histories (Table 2). A substantial minority (11\%) would repeat screening esophagoduodenoscopy (EGD) at a later date in a patient with GERD symptoms but a normal initial screening EGD. Likewise, a substantial minority $(17 \%)$ would perform surveillance EGD at an interval shorter than $3 \mathrm{yr}$ in a patient with Barrett's esophagus without dysplasia. Respondents were nearly evenly divided in their usual practice of surveillance of low-grade dysplasia between surveillance intervals of 3 months and $1 \mathrm{yr}$.

\section{Knowledge of Guidelines}

On average, gastroenterologists knew the ACG guideline for $59 \%$ of the scenarios. Overall, there was no significant difference in the knowledge of the guidelines between attendings and fellows, between those scheduled to take the certification or recertification exams and those not scheduled, between attendings with different compensation structures, or between attendings who had been identified in a malpractice suit and those who had not. Among attendings, there was no consistent association of either malpractice history or compensation structure with the knowledge of the guidelines for the individual scenarios. For instance, attendings who were prior malpractice defendants appeared to be more likely to know the recommended surveillance interval for Barrett's esophagus without dysplasia ( $88 \%$ vs $74 \%, P=0.07)$, but less likely to know the recommended management of low-grade dysplasia ( $38 \%$ vs $56 \%, P=0.07)$, and did not demonstrate differences regarding the knowledge of guidelines for the other scenarios.

\section{Belief in Efficacy of Surveillance}

Most gastroenterologists believed that appropriate screening and surveillance would prevent only a minority of EAC deaths (median perceived preventable 30\%, interquartile range $20-50 \%$ ) (Fig. 1). In contrast, most believed that screening would prevent a majority of CRC deaths (median perceived preventable $75 \%$, interquartile range 50-80\%) (Fig. 2). Eighty-five percent of respondents believed that screening and surveillance for EAC are less efficacious than screening for colorectal adenocarcinoma (Fig. 3). Fellows perceived screening and surveillance for EAC as more efficacious than did attendings (40\% vs $32 \%, P=0.04)$. Among attendings, neither compensation structure nor malpractice history was significantly associated with the perceived efficacy of screening and surveillance for EAC. However, attendings with financial incentive for performing endoscopy perceived a higher relative efficacy of screening and surveillance for EAC compared with CRC (productivity-based without salary 0.51 , salaried with productivity incentives 0.43 , and salaried without 
Table 2. Usual Practice in the Clinical Scenarios

\begin{tabular}{|c|c|c|}
\hline Scenario & Usual Practice & Response \\
\hline \multirow[t]{2}{*}{ 55-yr-old man with $20 \mathrm{yr}$ of daily GERD } & Screen & $98 \%$ \\
\hline & Do not Screen & $2 \%$ \\
\hline \multirow[t]{2}{*}{ 35-yr-old man with $20 \mathrm{yr}$ of GERD twice per week } & Screen & $73 \%$ \\
\hline & Do not Screen & $27 \%$ \\
\hline \multirow[t]{2}{*}{ 55-yr-old woman with $2 \mathrm{yr}$ of GERD } & Screen & $42 \%$ \\
\hline & Do not Screen & $58 \%$ \\
\hline \multirow[t]{2}{*}{ 35-yr-old woman with 2 yr of GERD } & Screen & $16 \%$ \\
\hline & Do not Screen & $84 \%$ \\
\hline \multirow{5}{*}{$\begin{array}{l}\text { GERD patient with normal screening EGD } \\
\text { (no Barrett's esophagus and no esophagitis) }\end{array}$} & No surveillance & $89 \%$ \\
\hline & EGD in 3 months & $0 \%$ \\
\hline & EGD in $1 \mathrm{yr}$ & $1 \%$ \\
\hline & EGD in $3 \mathrm{yr}$ & $4 \%$ \\
\hline & EGD in $5 \mathrm{yr}$ & $7 \%$ \\
\hline \multirow{6}{*}{$\begin{array}{l}\text { Screening EGD with biopsy reveals Barrett's esophagus without dysplasia. } \\
\text { Repeat EGD/histology } 12 \text { months later confirms this diagnosis. }\end{array}$} & No surveillance & $1 \%$ \\
\hline & EGD in 3 months & $1 \%$ \\
\hline & EGD in $1 \mathrm{yr}$ & $16 \%$ \\
\hline & EGD in $3 \mathrm{yr}$ & $79 \%$ \\
\hline & EGD in $5 \mathrm{yr}$ & $3 \%$ \\
\hline & Refer for esophagectomy & $0 \%$ \\
\hline \multirow{5}{*}{$\begin{array}{l}\text { Histology reveals Barrett's esophagus with low-grade dysplasia, } \\
\text { confirmed by expert pathologist. }\end{array}$} & EGD in 3 months & $50 \%$ \\
\hline & EGD in $1 \mathrm{yr}$ & $49 \%$ \\
\hline & EGD in $3 \mathrm{yr}$ & $0 \%$ \\
\hline & EGD in $5 \mathrm{yr}$ & $0 \%$ \\
\hline & Refer for esophagectomy & $0 \%$ \\
\hline \multirow{5}{*}{$\begin{array}{l}\text { Histology reveals Barrett's esophagus with multifocal high-grade dysplasia, confirmed by } \\
\text { expert pathologist. Repeat EGD } 3 \text { months later confirms the diagnosis. }\end{array}$} & EGD in 3 months & $12 \%$ \\
\hline & EGD in $1 \mathrm{yr}$ & $0 \%$ \\
\hline & EGD in $3 \mathrm{yr}$ & $0 \%$ \\
\hline & EGD in $5 \mathrm{yr}$ & $0 \%$ \\
\hline & Refer for esophagectomy & $88 \%$ \\
\hline
\end{tabular}

productivity incentives $0.34, P=0.05)$. There was no association between malpractice history and belief in the relative efficacy of screening and surveillance.

\section{Risk Factors for Malpractice Suits Among Attendings}

In univariable logistic regression among attendings, having been identified as a defendant in a malpractice suit was asso-

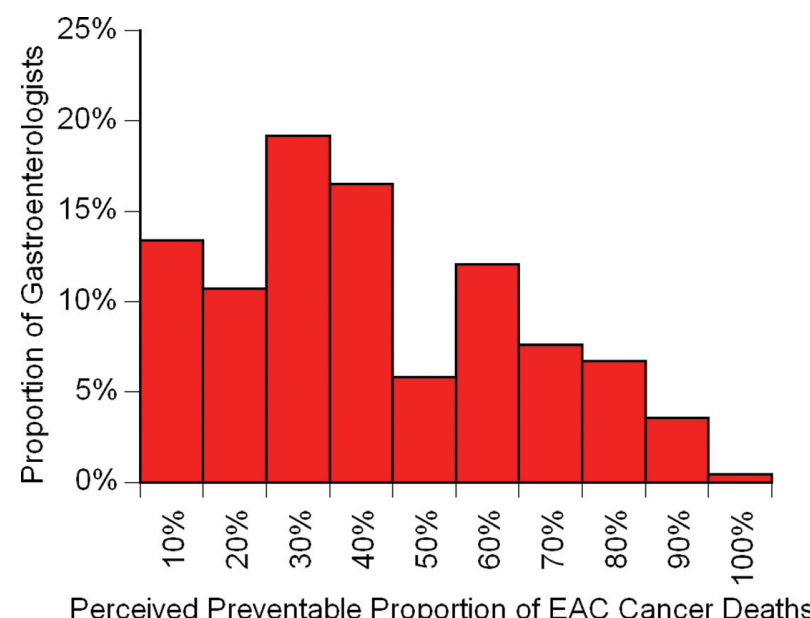

Figure 1. Perceived efficacy of screening and surveillance for esophageal adenocarcinoma. Each column represents the proportion of gastroenterologists who believe that appropriate screening and surveillance prevent that proportion of deaths from EAC. ciated with an increasing number of years in practice, higher volume of EGD performed on a weekly basis, private or mixed academic/private practice, male gender, and compensation by productivity without salary (Table 3 ). However, in multivariable stepwise forward logistic regression, only number of years in practice and volume of endoscopies remained significant (Table 3).

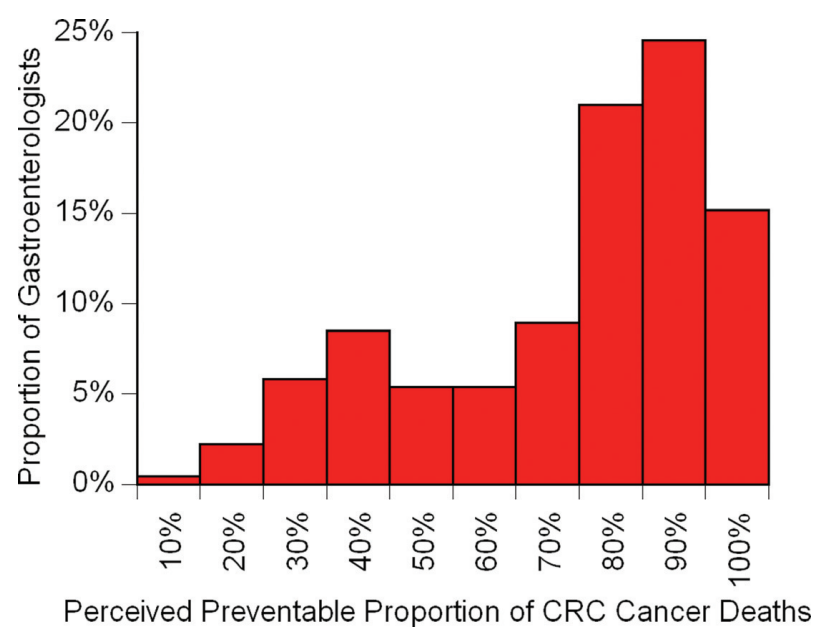

Figure 2. Perceived efficacy of screening for colorectal cancer. Each column represents the proportion of gastroenterologists who believe that appropriate screening and surveillance prevent that proportion of deaths from colorectal cancer (CRC). 


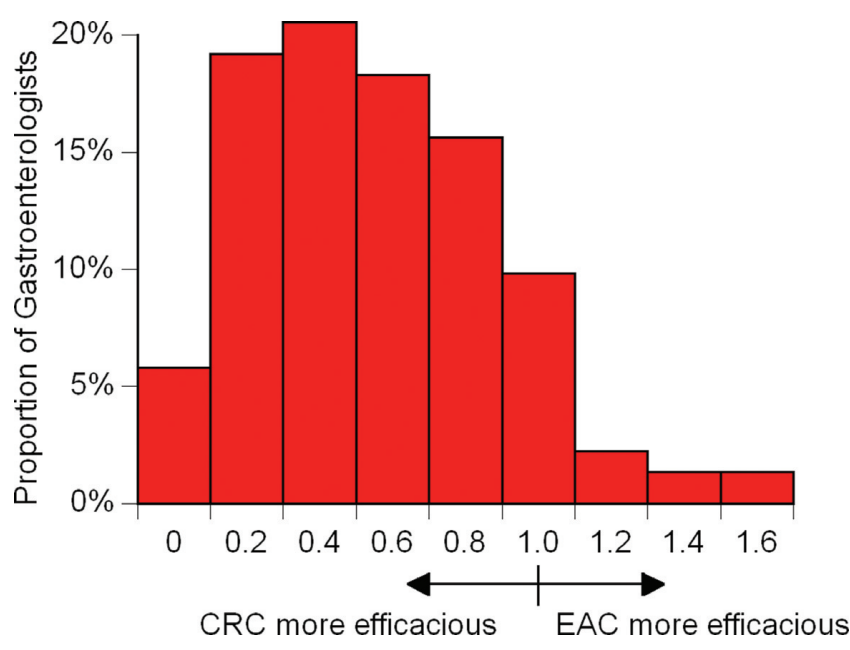

Figure 3. Perceived relative efficacy of screening for esophageal adenocarcinoma. Perceived relative efficacy was defined as the perceived efficacy of screening for esophageal adenocarcinoma (EAC) divided by the perceived efficacy of screening for colorectal cancer (CRC). Values greater than 1.0 imply a belief that screening for EAC is more efficacious than screening for CRC.

\section{Determinants of Practice Patterns Among Attendings}

In univariable logistic regression among attendings, aggressive use of screening and surveillance rather than conservative use was only significantly associated with the history of being identified as a defendant in a malpractice suit (OR 3.6, 95\% confidence interval [CI] 1.1-12) (Fig. 4). There was no association with the stated belief in the efficacy of screening for esophageal adenocarcinoma, but the results suggest the possibility that aggressive use may have been associated with perceived greater relative efficacy of screening for EAC compared with screening for CRC (OR 3.3, 95\% CI 0.87-12). Aggressive use of screening was not associated with compensation structure, volume of endoscopy, practice setting, type of private practice, years in practice, gender, or overall knowledge of ACG guidelines for the scenarios. After adjusting for

Table 3. Logistic Regression for Having Been Named in a Malpractice Suit

\begin{tabular}{|c|c|c|}
\hline Factor & $\begin{array}{l}\text { Unadjusted } \\
\text { Odds Ratio } \\
(95 \% \mathrm{CI})\end{array}$ & $\begin{array}{l}\text { Adjusted } \\
\text { Odds Ratio } \\
(95 \% \mathrm{CI})\end{array}$ \\
\hline \multicolumn{3}{|l|}{ Years in practicing GI $(v s<10 \mathrm{yr})$ : } \\
\hline $10-19$ yr & $2.2(0.87-5.6)$ & $3.2(1.0-9.6)$ \\
\hline$\geq 20 \mathrm{yr}$ & $3.1(1.1-8.4)$ & $4.0(1.3-12)$ \\
\hline$>10 \mathrm{EGD} /$ week & $11(2.5-47)$ & $24(3.1-193)$ \\
\hline $\begin{array}{l}\text { Private or mixed private/academic } \\
\text { practice } v s \text { academic practice }\end{array}$ & $7.4(0.97-57)$ & $3.8(0.44-32)$ \\
\hline $\begin{array}{l}\text { Productivity-based without salary } \\
v s \text { salaried without productivity } \\
\text { incentives }\end{array}$ & $2.8(1.1-7.4)$ & N/A \\
\hline Male gender & $4.2(1.2-15)$ & N/A \\
\hline
\end{tabular}

$\mathrm{CI}=$ confidence interval; $\mathrm{N} / \mathrm{A}=$ not applicable as the factor was not included in the multivariable model based on the likelihood ratio test. each other, prior malpractice suits remained significantly associated with aggressive screening and surveillance (OR 3.6, 95\% CI 1.03-12), and the results suggest the possibility that perceived relative efficacy of screening and surveillance may have been associated with aggressive screening and surveillance (OR 3.1, 95\% CI 0.83-12). The estimates remained the same, and malpractice history remained statistically significant, after additionally adjusting for overall knowledge of the ACG guidelines, or after adjusting for believing that the guidelines are consistent with one's usual practice.

In the individual scenarios, prior malpractice defendants were more likely to screen a 35-yr-old woman with $2 \mathrm{yr}$ of GERD $(38 \%$ vs $13 \%, P<0.01)$, more likely to survey every 3 months for low-grade dysplasia rather than annually ( $71 \%$ vs $49 \%, P=0.02$ ), and more likely to screen a 55 -yr-old woman with $2 \mathrm{yr}$ of GERD ( $56 \%$ vs 38\%, $P=0.06$ ). Among those who knew the recommended surveillance interval for low-grade dysplasia of $1 \mathrm{yr}$, the results suggest the possibility that prior malpractice defendants may have been more likely to disagree with the guideline, and instead perform endoscopy at 3 months, than those who knew the guideline but were not prior malpractice defendants (OR 2.8, 95\% CI 0.71-11).

Attending gastroenterologists who would usually screen a 35 -yr-old woman with $2 \mathrm{yr}$ of GERD perceived screening and surveillance for EAC as relatively more efficacious than did those who did not screen such patients (ratio of preventable deaths in EAC compared with CRC in those who screen was 0.66 vs 0.48 in those who do not screen, $P<0.01$ ). Similarly, those who would perform surveillance for Barrett's esophagus without dysplasia at intervals shorter than 3 yr perceived a greater relative efficacy of screening and surveillance for EAC than those who would perform surveillance at $3 \mathrm{yr}$ or longer intervals ( 0.66 vs $0.49, P=0.01)$.

\section{DISCUSSION}

We hypothesized that financial incentives and fear of malpractice litigation influence gastroenterologists to aggressively utilize services for screening and surveillance of Barrett's esophagus. In this survey of practicing gastroenterologists, we found a wide range of practice regarding screening and surveillance for Barrett's esophagus, and found that the only factors apparently influencing those practice patterns are prior malpractice suits and perceived relative efficacy of screening for preventing death. Financial incentives did not appear to influence the practice of screening and surveillance.

To our knowledge, this is the first study demonstrating an association between malpractice history and aggressive practice within the subspeciality of gastroenterology. A previous study in other specialties found no association between malpractice history and practice patterns in scenarios such as syncope or nonspecific electrocardiogram findings (18). The association of malpractice history and screening and surveillance for Barrett's esophagus may be due to the unsettled controversy regarding whether and whom to screen, and how to 


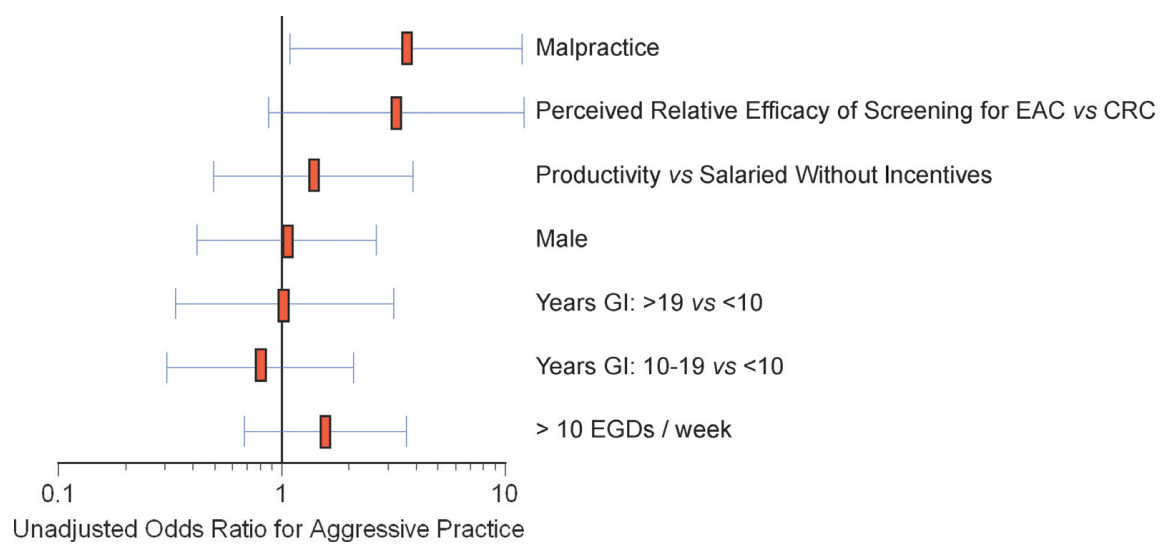

Figure 4. Unadjusted logistic regression for aggressive use of screening and surveillance compared with conservative use. Vertical bars represent point estimates of odds ratios for aggressive practice, and whiskers represent $95 \%$ confidence intervals. Note that the scale is logarithmic. Odds ratios for perceived relative efficacy of screening represent associations with 1-unit increases in the logtransformed value of that factor. A prior malpractice suit was the only factor statistically significantly associated with aggressive practice. Productivity-based compensation without salary was not associated with aggressive practice compared with salaried compensation without productivity incentives.

survey. One striking finding in this survey was the lack of consensus regarding which patients with chronic GERD symptoms should undergo initial screening other than middle-aged men with two decades of symptoms. This may reflect different practical conclusions drawn by gastroenterologists from the fact that duration of GERD symptoms and gender are inaccurate predictors of the presence of Barrett's esophagus $(19,20)$. These shortcomings are also reflected in the ambiguity of the published guidelines regarding screening. The ACG recommends screening patients with chronic GERD symptoms, but notes that "specific criteria to select patients to screen for Barrett's are not yet defined" (3). The American Society for Gastrointestinal Endoscopy states that screening "may be appropriate" in selected patients with long-standing, frequent GERD, and next mentions the higher risk in older, white men (6). The American Gastroenterology Association position statement notes that screening patients older than 50 yr with GERD symptoms "may be of value," which might be interpreted to imply that screening of younger patients is of no value (4). In light of the unsettled controversy regarding who should undergo screening, gastroenterologists who are more fearful of malpractice litigation (such as those who have been sensitized by a previous malpractice suit) may decide to err on the side of aggressively screening low-yield populations.

We also found considerable variation in the practice of surveillance. While the ACG and the American Society for Gastrointestinal Endoscopy have extended their recommended surveillance interval for patients with Barrett's esophagus without dysplasia to $3 \mathrm{yr}(3,6,21,22)$, and the American Gastroenterology Association recommends surveillance at $5 \mathrm{yr}$ (4), more gastroenterologists performed surveillance at intervals shorter than $3 \mathrm{yr}$ than longer than 3 yr. Furthermore, fully one-half of gastroenterologists perform surveillance for low-grade dysplasia at 3 months, rather than at $1 \mathrm{yr}$. This appears to be partly related to the inadequate knowledge regarding the recent uniformity among American societies' recommendations of annual surveillance in lowgrade dysplasia, but even among those who know the recommended interval, prior malpractice defendants appeared to be nearly 3 -fold more likely to perform more aggressive surveillance. These findings suggest uneasiness among prior malpractice defendants with a greater risk of an interval malignancy in these patients, and that this uneasiness may be allayed by more frequent surveillance. But as prior malpractice defendants hold similar beliefs regarding the efficacy of screening to those of the physicians who have not been previously identified in malpractice suits, the prior malpractice defendants' uneasiness may not be so much in regard to the patient's risk of cancer mortality (of which the gastroenterologist may feel that he/she has relatively little ability to prevent), but rather in regard to their own risk for litigation if the patient does die from cancer. The prior malpractice defendant likely recognizes that the risk of malpractice litigation is manageable by a defensive posture, which in part entails documenting an aggressive surveillance for cancer.

We failed to find any relationship between productivity incentives and aggressive practice of screening and surveillance. This may have been due to the limitations in the measures we used for these factors. If there truly is no relationship, then this suggests that gastroenterologists with productivity incentives either do not value those incentives heavily in comparison to the risks and benefits of the procedures experienced by their patients or may encounter competing priorities, such as screening colonoscopies. It also suggests that the costs associated with a settled or lost malpractice suit, albeit of a low likelihood to result from an encounter with any individual patient, are considered more important to the gastroenterologist than the definite, but relatively small, reward of performing an additional endoscopy.

Our study is limited in that we did not measure actual practice, but relied on self-reported practice. We also did 
not measure fear of litigation, which could also explain the behavior among gastroenterologists who have not been previously identified in a malpractice suit. We did not measure physician quality, which may confound prior malpractice history. However, the association of prior malpractice suits with practice patterns remained after adjusting for knowledge of a published guideline. The results may not be generalizable, as sampling of physicians attending a board review course may have biased the results in an unpredictable manner; however, we did not find any independent association between aggressiveness and years in practice or age. Finally, the sample size resulted in a wide confidence interval, and may have limited the ability to detect small associations between practice pattern and compensation structure or other factors. In particular, the main effect studied (between malpractice history and aggressive practice) had a wide confidence interval, and the lower limit approached the null value. Larger studies with more precise measures of fear of malpractice are needed to verify these results.

In the setting of a bad outcome, such as a cancer death or a procedural complication, jurors may be more likely to judge against physicians who practice in an unusual manner, regardless of whether the action leading to that outcome was due to an act of omission (i.e., refraining from screening or performing surveillance only infrequently) or of commission (performing screening or frequent surveillance) (23). Practice guidelines may be used as exculpatory or inculpatory evidence in court (although they may not always be admissible in court, or may be refuted by expert testimony); guidelines that appear to offer exculpatory evidence may influence attorneys not to bring suit $(24,25)$. As the published guidelines for Barrett's esophagus either do not address screening or contradict each other, a gastroenterologist who wants to minimize his or her risk of litigation is left in a quandary. Apparently, prior malpractice defendants in our sample chose to err on the side of commission rather than omission, even though the risk of cancer is lower than the risk of a procedural complication among low-yield patients (26). Their practice may be due to a recognition that acts of omission are less likely to be successfully defended, even though acts of omission represent less than $10 \%$ of malpractice claims (27).

The influence of malpractice concerns on practice of screening and surveillance may be somewhat unique to EAC due to the lack of high-quality data on the efficacy of screening. In this same survey, we were not able to find a statistically significant association between malpractice history and aggressive practice of screening for CRC (OR 1.9, 95\% CI 0.68-5.3). Intensive use of endoscopic resources, secondary to concerns over litigation, might be reduced if the guidelines of major societies uniformly stated that screening for EAC should not be performed in low-risk groups. A logical initial threshold on which to obtain unanimity would be on the basis of age. Although the incidence of EAC is increasing, the incidence is increasing much more quickly among older populations: it is still very rare for a patient to develop this cancer type before the age of 50 years (1). As Barrett's esophagus appears to develop before this age $(28,29)$, performing screening at age 50 should also obviate the practice of $11 \%$ of our respondents of performing repeated endoscopies in patients found not to have Barrett's esophagus. Nonetheless, improved dissemination and uptake of recommendations would still be required in order to sufficiently impact practice patterns.

In summary, we found substantial variation in the practice of screening and surveillance for Barrett's esophagus. Prior malpractice suits appear to influence the intensity of screening and surveillance, but financial incentives to perform additional endoscopies do not. Whether aggressive practice of screening and surveillance is a rational response to the risk of litigation, or if it is an overreaction, ought to be investigated.

\section{ACKNOWLEDGMENT}

We greatly appreciate William Steinberg, M.D, for allowing us to distribute the surveys at his board review course.

\section{STUDY HIGHLIGHTS}

\section{What Is Current Knowledge}

- Screening and surveillance for Barrett's esophagus is controversial.

- The practice of surveillance for Barrett's esophagus is variable.

- Little is known regarding screening patterns for Barrett's esophagus.

- Little is known regarding what factors influence gastroenterologists' practice of screening and surveillance for Barrett's esophagus.

\section{What Is New Here}

- Gastroenterologists vary considerably regarding which patients they screen for Barrett's esophagus.

- Prior malpractice defendants are more aggressive in screening and surveillance of Barrett's esophagus.

- Financial incentives do not appear to significantly influence screening and surveillance for Barrett's esophagus.

Reprint requests and correspondence: Joel H. Rubenstein, M.D., M.Sc., Ann Arbor Veterans Affairs Medical Center (111-D), 2215 Fuller Road, Ann Arbor, MI 48105.

Received June 28, 2007; accepted October 12, 2007.

\section{REFERENCES}

1 El-Serag HB, Mason AC, Petersen N, et al. Epidemiological differences between adenocarcinoma of the oesophagus and adenocarcinoma of the gastric cardia in the USA. Gut 2002;50:368-72. 
2 Portale G, Peters JH, Hagen JA, et al. Comparison of the clinical and histological characteristics and survival of distal esophageal-gastroesophageal junction adenocarcinoma in patients with and without Barrett mucosa. Arch Surg 2005; 140:570-4.

3 Sampliner RE. Updated guidelines for the diagnosis, surveillance, and therapy of Barrett's esophagus. Am J Gastroenterol 2002;97:1888-95.

4 Wang KK, Wongkeesong M, Buttar NS, et al. American Gastroenterological Association medical position statement: Role of the gastroenterologist in the management of esophageal carcinoma. Gastroenterology 2005;128:146870.

5 Boyer J, Robaszkiewicz M. Guidelines of the French Society of Digestive Endoscopy: monitoring of Barrett's esophagus. The Council of the French Society of Digestive Endoscopy. Endoscopy 2000;32:498-9.

6 Anonymous. ASGE guideline: The role of endoscopy in the surveillance of premalignant conditions of the upper GI tract. Gastrointest Endosc 2006;63:570-80.

7 Sharma P, McQuaid K, Dent J, et al. A critical review of the diagnosis and management of Barrett's esophagus: The AGA Chicago Workshop. Gastroenterology 2004;127:310 30.

8 Watson A, Heading RC, Shepherd NA. Guidelines for the diagnosis and management of Barrett's columnarlined oesophagus. Available at: http://www.bsg.org.uk/ bsgdisp1.php?id=3f4a76385e42599499e9\&h=1\&sh= $1 \& \mathrm{i}=1 \& \mathrm{~b}=1 \& \mathrm{~m}=00023$. Accessed January 22, 2007.

9 Armstrong D, Marshall JK, Chiba N, et al. Canadian Consensus Conference on the management of gastroesophageal reflux disease in adults - update 2004. Can J Gastroenterol 2005;19:15-35.

10 Rice TW, Blackstone EH, Rybicki LA, et al. Refining esophageal cancer staging. J Thorac Cardiovasc Surg 2003; 125:1103-13.

11 Falk GW, Ours TM, Richter JE. Practice patterns for surveillance of Barrett's esophagus in the United States. Gastrointest Endosc 2000;52:197-203.

12 Cruz-Correa M, Gross CP, Canto MI, et al. The impact of practice guidelines in the management of Barrett esophagus: A national prospective cohort study of physicians. Arch Intern Med 2001;161:2588-95.

13 Moss A, Clarke E, Crowe J, et al. Management of Barrett's oesophagus in 2001 in Ireland. Ir J Med Sci 2003;172:174 6.

14 Shen EF, Gladstone S, Milne G, et al. Endoscopic surveillance practice for Barrett's oesophagus in Scotland and early experience in implementing local guidelines. Scott Med J 2003;48:43-5.

15 MacNeil-Covin L, Casson AG, Malatjalian D, et al. A survey of Canadian gastroenterologists about the management of Barrett's esophagus. Can J Gastroenterol 2003;17:313-7.

16 van Sandick JW, Bartelsman JF, van Lanschot JJ, et al. Surveillance of Barrett's oesophagus: Physicians' practices and review of current guidelines. Eur J Gastroenterol Hepatol 2000;12:111-7.

17 Lin OS, Mannava S, Hwang KL, et al. Reasons for current practices in managing Barrett's esophagus. Dis Esophagus 2002;15:39-45.

18 Glassman PA, Rolph JE, Petersen LP, et al. Physicians' personal malpractice experiences are not related to defensive clinical practices. J Health Polit Policy Law 1996;21:21941 .
19 Locke GR, Zinsmeister AR, Talley NJ. Can symptoms predict endoscopic findings in GERD? Gastrointest Endosc 2003;58:661-70.

20 Gerson LB, Edson R, Lavori PW, et al. Use of a simple symptom questionnaire to predict Barrett's esophagus in patients with symptoms of gastroesophageal reflux. Am J Gastroenterol 2001;96:2005-12.

21 Sampliner RE. Practice guidelines on the diagnosis, surveillance, and therapy of Barrett's esophagus. The Practice Parameters Committee of the American College of Gastroenterology. Am J Gastroenterol 1998;93:1028-32.

22 Anonymous. The role of endoscopy in the surveillance of premalignant conditions of the upper gastrointestinal tract. Gastrointest Endosc 1998;48;663-8.

23 Prentice RA, Koehler JJ. A normality bias in legal decision making. Cornell Law Rev 2003;88:583-650.

24 Matthews JR. Practice guidelines and tort reform: The legal system confronts the technocratic wish. J Health Polit Policy Law 1999;24:275-304.

25 Hyams AL, Brandenburg JA, Lipsitz SR, et al. Practice guidelines and malpractice litigation: A two-way street. Ann Intern Med 1995;122:450-5.

26 Shaheen NJ. Advances in Barrett's esophagus and esophageal adenocarcinoma. Gastroenterology 2005;128: 1554-66.

27 Kravitz RL, Rolph JE, Petersen L. Omission-related malpractice claims and the limits of defensive medicine. Med Care Res Rev 1997;54:456-71.

28 van Soest EM, Dieleman JP, Siersema PD, et al. Increasing incidence of Barrett's oesophagus in the general population. Gut 2005;54:1062-6.

29 Sontag SJ, Leya J, Schnell T, et al. Barrett's esophagus develops during youth or when we are born - not during adulthood. Part 5 in a series: The origins of GERD [abstract]. Gastroenterology 2004;126(Suppl 2):A308.

\section{CONFLICT OF INTEREST}

Guarantor of the article: Joel H. Rubenstein, M.D., M.Sc. Specific author contributions: Joel H. Rubenstein devised the hypothesis, participated in the design, performed and interpreted the statistical analyses, and drafted the manuscript. Sameer D. Saini and Pratima Sharma each participated in the design and interpretation of the results and edited the manuscript. Latoya Kuhn entered the data into electronic format and cleaned the data. Laurence McMohan participated in devising the hypothesis, interpretation of the results, and edited the manuscript. Darrell S. Pardi participated in interpreting the results and edited the manuscript. Philip Schoenfeld participated in devising the hypothesis, administered the surveys, participated in interpretation of the results, and edited the manuscript.

Financial support: Joel H. Rubenstein was funded by a Clinical Investigators Award from the Damon Runyon Cancer Research Foundation.

Potential competing interests: None. 